Trinity University

Digital Commons@ Trinity

Biology Faculty Research

Biology Department

$11-2019$

\title{
Ritualized Display of a Leaf: A Putative Agonistic Signal in Both Sexes of Tropical Bird
}

\author{
L. M. Kiere
}

Troy G. Murphy

Trinity University, tmurphy@trinity.edu

A. Garcia-Muñoz

M. Osorio-Beristain

Follow this and additional works at: https://digitalcommons.trinity.edu/bio_faculty

Part of the Biology Commons

\section{Repository Citation}

Kiere, L.M., Murphy, T.G., García-Muñoz, A., \& Osorio-Beristain, M. (2019). Ritualized display of a leaf: A putative agonistic signal in both sexes of a tropical bird. Behavioural Processes, 168, forthcoming. doi: 10.1016/j.beproc.2019.103954

This Article is brought to you for free and open access by the Biology Department at Digital Commons @ Trinity. It has been accepted for inclusion in Biology Faculty Research by an authorized administrator of Digital Commons@ Trinity. For more information, please contact jcostanz@trinity.edu. 


\title{
Ritualized display of a leaf: A putative agonistic signal in both sexes of a tropical bird
}

\author{
Lynna Marie Kiere ${ }^{\mathrm{a}, *, 1}$, Troy G. Murphy ${ }^{\mathrm{b}, 1}$, America García-Muñoz ${ }^{\mathrm{a}}$, Marcela Osorio-Beristain ${ }^{\mathrm{a}}$ \\ ${ }^{a}$ Centro de Investigación en Biodiversidad y Conservación, Universidad Autónoma del Estado de Morelos, Cuernavaca, Morelos, Mexico \\ ${ }^{b}$ Departament of Biology, Trinity University, San Antonio, TX, United States
}

\section{A R T I C L E I N F O}

\section{Keywords:}

Props

Aggression

Sex roles

Territoriality

Behavioral display

Motmot

\begin{abstract}
A B S T R A C T
Birds use many different signaling modalities (e.g. vocalizations, displays) to transmit information about their motivation to defend valuable resources. A handful of taxa use "props", inedible objects scavenged from the environment, in signaling. Several species of motmots (Coraciiformes) hold a leaf in their bill in a display that observational evidence suggests is agonistic. We used a simulated intruder experiment to test this display's agonistic signaling function using data from both members of pairs of russet-crowned motmots (Momotus mexicanus). If the display is agonistic, we expected territory-holding pairs to respond more strongly toward taxidermic mounts displaying a leaf. Our results showed that resident pairs reacted differently to the leaf display depending on the intruder's sex. Display of a leaf by the intruder increased the closeness of the pairs' approach when the model was male, but increased the probability of the territorial defenders displaying a leaf themselves when the model was female. Pairs spent more time responding to male models regardless of leaf display. Our results suggest that the leaf display is an agonistic signal, that territory owners react differently to the leaf display depending on the sex of the intruder performing it, and that the participation of both sexes in territorial defense-which is common among tropical resident birds-extends to this unusual signaling modality.
\end{abstract}

\section{Introduction}

Agonistic signals are used throughout the animal kingdom to transmit information about an individual's ability and/or motivation to defend a valuable resource while avoiding, or at least delaying, the risks and costs of a physical fight. In birds, agonistic signals can take many forms or "modalities," from coloration of plumage (e.g. gold and black crown patches in golden-crowned sparrows, Chaine et al., 2013) or soft tissues (e.g. bill color in American goldfinches, Murphy et al., 2009), to visual behavioral displays (e.g. "wing wave display" in swamp sparrows, Anderson et al., 2013) and vocalizations (review in Searcy and Beecher, 2009b). The agonistic signaling function of birdsong has been the subject of a particularly large body of theoretical and experimental literature (e.g. reviews in Bradbury and Vehrencamp, 1999; Laidre and Vehrencamp, 2008; Searcy and Beecher, 2009b). It was in this context that Searcy and Beecher (2009b) proposed that signals of individuals' motivation to escalate a conflict ("aggressive signals") should be defined by three criteria: 1) the "context criterion"- whether the signal is more frequent during agonistic interactions, 2) the "predictive criterion"- whether the signal predicts escalation of the conflict, and 3) the "response criterion"- whether receivers respond when the signal is given. However, while originally proposed for vocalizations, these criteria have been applied to understanding other dynamic signaling modalities ("wing wave" display in swamp sparrows; Anderson et al., 2013).

An interesting but relatively rare signaling modality in birds is the use of "props"-inedible objects scavenged from the environment. Props can be incorporated into structures such as nests or display arenas, or into behavioral displays. Perhaps the most iconic examples of prop use in birds-the use of colored objects to decorate "bowers" by male bowerbirds (Ptilonorhynchidae) and "petal carrying" by male fairy wrens (Maluridae) -are primarily sexual signals used in mate attraction (reviewed in Montgomerie, 2006). However, there is a growing number of examples suggesting that props can have agonistic functions, particularly when integrated into structures. Piles of prey feathers left by eagle owls (Bubo bubo) are thought to indicate territory occupation (Penteriani and del Mar Delgado, 2008), heterospecific feathers in the nests of rock sparrows (Petronia petronia) may be a signal

\footnotetext{
* Corresponding author at: Centro de Investigación en Biodiversidad y Conservación, Universidad Autónoma del Estado de Morelos, Avenida Universidad 1001, Chamilpa, Cuernavaca, Morelos, 62209, Mexico.

E-mail address: lynnamariekiere@gmail.com (L.M. Kiere).

${ }^{1}$ These authors should be considered joint first authors.
} 
of the owner's competitive status (García-Navas et al., 2015), and the amount of white plastic included in the nests of black kites (Milvus migrans) has been demonstrated to honestly indicate territory holders' quality and decrease territorial intrusion (Sergio et al., 2011). On the other hand, we know of only one avian group that is suspected to integrate props into a behavioral display performed in an antagonistic context: the motmots (Momotidae), a family of neotropical Coraciiformes (reviewed in Murphy, 2008).

Four of the ten species of motmots have been observed performing a "leaf display" (reviewed in Murphy, 2008). This display has been studied in most detail in the turquoise-browed motmot (Eumomota superciliosa), where both sexes perform the display and several lines of evidence suggest a primarily agonistic rather than sexual function (Murphy, 2008). In that species, the display consists of picking up and holding a leaf horizontally in the tip of the bill, sometimes for up to an hour. The leaf may be plucked fresh or dry from a tree or picked up from the ground, and they vary in color from fresh green leaves to yellow or brown dead leaves (Murphy, 2008). In the turquoise browed motmot, the leaf display is performed both before and after pair formation, by both paired and unpaired individuals, often just before a chase or fight, frequently at the entrance of the nest tunnel upon the approach of a potential intruder, and often in conjunction with a common agonistic display ("scoot display"; Murphy, 2008). In the motmot species used in this study, the russet-crowned motmot (Momotus mexicanus) from central Mexico, the leaf display is performed year-round by territorial males and females (Murphy pers. obs.), though systematic observations of the frequency and context of the display in this species have not been carried out.

Several aspects of the russet-crowned motmot's life history suggest that the territory is a valuable resource that both members of the pair should be motivated to defend from potential usurpers, as is the case in many tropical resident birds (reviewed in Stutchbury and Morton, 2001). Like all other motmots, $M$. mexicanus is an obligate primary cavity nester (Howell and Webb, 1995). Both sexes participate in excavating a new $0.88-1.71 \mathrm{~m}$ deep nest tunnel or remodeling an existing tunnel in earthen banks along rivers or roadsides, near which they vocalize in call-and-response duets (Murphy et al., 2010; Charre et al., 2017). Re-sighting of a marked individual in the same site ten years after banding confirms that these motmots are relatively long-lived ( $~ 11$ years) and suggests high site fidelity (Murphy et al., 2010), which is also implied by the strong genetic structuring over very short distances found by Reyes et al. (2009). Nest tunnel collapse and flooding are major sources of nesting failure and are highly influenced by nesting substrate characteristics including soil texture, especially in high-precipitation years (Charre et al., 2017). The russet-crowned motmot is territorial during both the breeding and non-breeding seasons (Murphy pers. obs.), suggesting they defend breeding areas as future breeding sites or as "multi-purpose territories". The territory, including suitable nesting substrate, is therefore likely a highly valuable, limiting, and long-term resource, expected to generate competition and lead to agonistic interactions, including agonistic signals to mediate those interactions, between current territory holders and potential usurpers (Bradbury and Vehrencamp, 1999).

Here, we evaluate whether the leaf display functions as an agonistic signal in russet crowned motmots by comparing territory holders' responses toward a simulated intruder with and without the leaf display. Taxidermic models of both sexes were used to simulate territorial intrusion, and experiments were conducted in the post-breeding season to minimize confusion between possible mate-choice and agonistic functions. We quantified the resident pair's response using five variables: 1) total response time, 2) probability that at least one pair member would approach the intruder to within $10 \mathrm{~m}, 3$ ) distance of the closest approach by either pair member, 4) probability that either pair member would perform the leaf display, and 5) number of duets performed. If the leaf display functions as an agonistic signal, we expected increased intensity of the territorial response by pairs when they encountered models that displayed a leaf compared to models with no leaf (increase in all measures except distance of closest approach, which we expected to decrease). We also considered the possibility that a pair's territorial responses in general, and their response to the leaf display in particular, would depend on the sex of the intruder (significant effect of intruder sex or the interaction of intruder sex with intruder leaf display, respectively).

\section{Methods}

\subsection{Study site and species}

The study was conducted from mid-July to early-August 2008 in the Reserva de la Biosfera Sierra de Huautla, a tropical dry forest near the village of Huautla in the south-central Mexican state of Morelos $\left(18^{\circ} 26^{\prime} 21^{\prime \prime} \mathrm{N}, 9^{\circ} 01^{\prime 2} 27^{\prime \prime} \mathrm{W}\right)$. The site is composed of patches of preserved seasonally dry tropical forest, secondary vegetation, and agricultural fields and grazing pastures. The most conspicuous canopy trees are Conzantia multiflora, Lysiloma acapulcense, L. divaricatum, Bursera spp, and Ceiba spp (CONANP, 2005).

Russet-crowned motmots breed during the rainy season, with chicks generally fledging by early July in our study region (Murphy et al., 2010; Gaviño de la Torre, 2015). This species is not known to raise more than one successful brood per season, though they may re-nest following nest failure (Murphy et al., 2010; Charre et al., 2017). Thus, young had already fledged by the time the study began, and none of our focal pairs were actively caring for fledglings. In a previous study, both the male and female in eight color-banded pairs were observed feeding young; this suggests that this species is socially monogamous and that both sexes participate in chick rearing (Murphy et al., 2010). However, the genetic mating system, average pair bond duration, rates of mateswitching, and rates of extra-pair paternity or within-species brood parasitism have not been explored. Males and females do not differ in overall body size and are not noticeably different in plumage to human observers (though their plumage has not been studied in depth to determine whether there are differences in UV coloration or other aspects of plumage or morphology that are not apparent to humans).

During the leaf display, birds collected plant material from the ground or directly from trees, as described in the turquoise browed motmot. In previous observations and during this study, russet-crowned motmots have been observed performing a similar display with a twig rather than a leaf (Murphy pers. obs.), which we considered a "leaf display" for the purposes of the study. A total of $\mathbf{3 0}$ territories located along the riverbank were initially identified, primarily by the presence of a male and female that duetted near a $\sim 10 \mathrm{~cm}$-diameter hole (possible nesting site). Males and females are distinguishable by voice (particularly when duetting) because males' song is noticeably louder and lower-pitched than females' (Murphy, unpublished data).

\subsection{Simulated intruder presentation}

Taxidermic models of each sex were prepared for use as simulated territory intruders. Five male and five female motmots were collected by mist netting $\geq 5 \mathrm{~km}$ from the study site to ensure experimental pairs would be presented with unfamiliar individuals. These ten individuals were sacrificed immediately following removal from the mist net and subsequently prepared using standard taxidermic methods with glass eyes and placed into a lifelike perched posture. The collection of these individuals and territorial intrusion experiments were authorized by permit \#FAUT 0169 granted by the Mexican Secretary of the Environment and Natural Resources (SEMARNAT) and approved by the Institutional Animal Care and Use Committee (IACUC) at Queen's University, the institution with which TGM was affiliated at the time of fieldwork (Permit code: Montgomerie0708AnCare).

In each of the 30 identified territories, the pair was presented with a simulated territorial intruder on two occasions: once with and once 
without a green leaf in its bill (leaf display), with ten days between the two presentations. We balanced the presentation order of leaf display for each territory by alternating whether a leaf was presented first. The same model was used for both presentations, with half of the territories presented with male models, and half with female models. To reduce the effect of pseudoreplication, intruders were randomly selected from a pool of 5 models of each sex (McGregor, 2000). For each presentation, the intruder was placed on a $1 \mathrm{~m}$ tall natural branch perch (the same perch was used throughout the experiment), and a speaker was placed below the model. We used a recording of duetting motmots to alert the territory owners to the presence of the potential territorial intruders and attract them close enough to the site of the model presentation to perceive and respond to the visual stimulus of the model. We played a single recording of a duetting pair of motmots throughout the trial on a loop composed of $30 \mathrm{~s}$ of vocalization followed by $60 \mathrm{~s}$ of silence, using the same recording for all trials. Speaker volume was set at the same level for all experiments, and both the duration and broadcast amplitude were comparable to natural vocalizations. All trials were conducted between 07:00 and 09:30 local time (GMT -6), and the two trials (separated by 10 days) on each territory had a start time within $20 \mathrm{~min}$ of each other, with the model and speaker in the same location and orientation for both presentations. Neighboring territories were not tested on the same day.

Using binoculars and spotting scopes from a portable blind $30 \mathrm{~m}$ from the model, two observers (LMK and AGM) monitored the responses of the male and female, with each observer collecting continuous behavioral data for one of the pair members. The focal birds vocalized frequently (on average approximately 100 times during the 20-min trial, or once every $12 \mathrm{~s}$ ), making it feasible to distinguish between the two individuals throughout the trial. Landmarks were established before trials began to indicate $30 \mathrm{~m}$ and $10 \mathrm{~m}$ radii around the model. There was a 5-minute habituation period after the model and speaker were placed and the observers returned to the blind to allow the pair to recover from any possible disturbance from the observers' approach, then the vocalization recording was played for $20 \mathrm{~min}$. We collected continuous behavioral data using a voice recorder during the model presentation period, noting each individual's movements, distance from the model, vocalizations, approaches, and attacks (flying up to and physically striking the model) as they occurred. The fact that attacks occurred strongly suggests that the model presentation was recognized as a territorial intrusion.

Behavioral variables were calculated from voice recordings after concluding all trials. We calculated the total response time (sum of the time in seconds that each pair member spent within $30 \mathrm{~m}$ of the model; i.e. if both pair members spent the entire trial within $30 \mathrm{~m}$ of the model, the total response time value would be 2400) and distance of closest approach (minimum of distance approached by either member of the pair; when an individual attacked the model, the distance of closest approach was zero). The approach within $10 \mathrm{~m}$ and leaf display variables were binary, receiving a value of 1 if at least one member of the pair performed the focal behavior at any time during the trial. Finally, we analyzed the number of duets performed by the pair during the trial. Fieldwork was conducted in accordance with ABS/ASAB guidelines (Animal Behaviour Society, 2012) and Mexican law, under SEMARNAT permit \#FAUT 0169 and IACUC permit Montgomerie0708AnCare from Queen's University.

\subsection{Statistical analysis}

Generalized linear mixed models were used to analyze behavioral data. We only included trials in which both pair members approached to within $30 \mathrm{~m}$ of the model. In 17 territories both pair members responded during both trials (i.e. a total of 34 trials), in 11 territories both individuals responded during only one of the trials (i.e. 11 trials), and two territories were excluded from analysis because only one individual responded. This yielded a total sample size of 45 trials from 28 territories. Territory and order of simulated territorial intrusion (first or second) were included as crossed random intercept terms to account for repeated measures of the pair's response and to account for habituation or sensitization to the intruder presentation. All analyses were carried out in R ( $\mathrm{R}$ development core team, 2014) using the RStudio interface (RStudio, 2012). The response duration and number of duets were modeled as linear mixed models using the lme4 package (Bates et al., 2004). Distance of closest approach was modeled using a generalized linear mixed model with a negative binomial error distribution and log link using the glmmTMB package (Brooks et al., 2017), and binary variables (approach to $10 \mathrm{~m}$ and leaf display) were modeled using a logit link and binomial error distribution using the lme4 package (Bates et al., 2004). The initial models included model sex, model leaf display, and their interaction (in order to detect whether pairs responded differently to the leaf display when performed by a particular sex of intruder). Initial models were simplified by backwards stepwise simplification, removing interactions followed by main effects one by one, from lowest to highest significance, comparing sequential models using ANOVA likelihood ratio tests until only terms whose removal provoked significant worsening of model fit remained (Crawley, 2007). Homoscedasticity, normality, and dispersion of model residuals were verified using the DHARMa package (Hartig, 2019). Whenever the interaction of model sex and model leaf display was significant, we made post-hoc comparisons to determine whether there was an effect of leaf display within each model sex using estimated marginal means (emm) from the minimum adequate model using the emmeans package (Lenth, 2018) with false discovery rate correction of $P$-values to account for multiple comparisons.

\section{Results}

Pairs spent an average of $1236.67 \pm 83.01 \mathrm{~s}$ (of a total possible $2400 \mathrm{~s}$ ) within $30 \mathrm{~m}$ of the model. The total time pairs spent within $30 \mathrm{~m}$ of the model was significantly greater when the model was male (an increase of $433 \pm 167 \mathrm{~s}$ compared to female models), with no effect of model leaf display or the interaction of model leaf display with model sex (Table 1a, Fig. 1a).

In 32 of the total 45 pair responses observed (71\%), at least one member of the pair approached to within $10 \mathrm{~m}$ of the model. In four responses, only one of the pair members approached, while in the majority of responses (28), both members approached to within $10 \mathrm{~m}$. The probability that at least one member of the pair would approach was affected by the interaction of model sex and model leaf display (Table 1b, Fig. 1b); pairs were significantly more likely to approach to within $10 \mathrm{~m}$ of a male model with a leaf than a male model with no leaf (emm contrast: $\beta=1.15 \pm 0.59, P=0.05$ ), but displaying a leaf had no effect on approach if the model was female (emm contrast: $\beta=$ $-0.47 \pm 0.50, P=0.35$ ).

The minimum distance approached by either pair member averaged $10.09 \pm 1.16 \mathrm{~m}$. Minimum distance was also affected by the interaction of model sex and model leaf (Table 1c, Fig. 1c). Like the probability of approaching within $10 \mathrm{~m}$, pairs approached models displaying a leaf more closely when the model was male (emm contrast: $\beta=$ $-0.34 \pm 0.16, P=0.04$ ), but leaf display did not have an effect when the model was female (emm contrast: $\beta=0.23 \pm 0.17, P=0.17$ ). During five of the trials (9\%), territory owners attacked the model. In four of those trials, only the male attacked, and in one trial, both pair members attacked. Two attacks were on male models displaying a leaf, one was on a male model without a leaf, and two were on female models without a leaf (there were no attacks on a female model with a leaf). Only one of the attacks occurred during the second visit to the territory, perhaps because pairs became habituated to the models' lack of response upon close approach. This, coupled with the small total number of attacks precludes us from formally analyzing or drawing any firm conclusions based on the distribution of these attacks.

The leaf display was performed by at least one of the pair members 
Table 1

Results of five separate linear (LMM) or generalized linear mixed models (GLMM) evaluating effects of model sex, model leaf display, and their interaction on the territorial responses of russet crowned motmot pairs. Bold print indicates variables retained in the minimum adequate model. $\beta, \mathrm{SE}$, and $Z$ values are from the minimum adequate model, and therefore are only given for variables that were retained during backwards stepwise simplification (bold). $\chi^{2}$ and $P$-values are from the nested model comparison following removal of each variable during backwards stepwise simplification.

\begin{tabular}{|c|c|c|c|c|}
\hline Fixed Effects & $\beta \pm S E$ & $\mathrm{z}$ & $\chi^{2}$ & $P_{\chi^{2}}$ \\
\hline \multicolumn{5}{|c|}{ a) Pair total response time (Sum of male and female $s$ within $30 \mathrm{~m}$; LMM) } \\
\hline Model Sex * & - & - & 1.62 & 0.20 \\
\hline \multicolumn{5}{|l|}{ Model Leaf } \\
\hline Model Sex & $433.2 \pm 167.3$ & 2.59 & 6.02 & 0.014 \\
\hline \multicolumn{5}{|c|}{$\begin{array}{l}\text { Random effects: } \sigma_{\text {Territory }}^{2}=9.47 \times 10^{4}, \sigma_{\text {Visit }}^{2}=0 \\
\text { b) Pair probability of approach within } 10 \mathrm{~m} \text { (approach by } \geq 1 \text { pair member; binomia } \\
\text { GLMM) }\end{array}$} \\
\hline $\begin{array}{l}\text { Model Sex * } \\
\quad \text { Model Lea }\end{array}$ & $3.25 \pm 1.56$ & \multicolumn{2}{|c|}{ Model Leaf } & 0.024 \\
\hline Model Leaf & $-0.94 \pm 1.00$ & -0.94 & 0.80 & 0.37 \\
\hline Model Sex & $-1.50 \pm 0.97$ & -1.55 & 0.05 & 0.82 \\
\hline \multicolumn{5}{|c|}{$\begin{array}{l}\text { Random effects: } \sigma_{\text {Territory }}^{2}=3.38 \times 10^{-14}, \sigma_{\mathrm{Visit}}^{2}=1.03 \times 10^{-12} \\
\text { c) Distance of closest approach (minimum distance between the model and either pai } \\
\text { member; negative binomial GLMM) }\end{array}$} \\
\hline $\begin{array}{l}\text { Model Sex * } \\
\quad \text { Model Lea }\end{array}$ & $-1.126 \pm 0.467$ & -2.41 & 5.33 & 0.021 \\
\hline Model Sex & $0.455 \pm 0.333$ & 1.37 & $\mathbf{0}$ & 0.17 \\
\hline Model Leaf & $0.546 \pm 0.325$ & 1.68 & 0.234 & 0.094 \\
\hline \multicolumn{5}{|c|}{$\begin{array}{l}\text { Random effects: } \sigma_{\text {Territory }}^{2}=5.48 \times 10^{-3}, \sigma_{\text {Visit }}^{2}=1.22 \times 10^{-7} \\
\text { d) Probability of leaf display (binomial GLMM) }\end{array}$} \\
\hline $\begin{array}{l}\text { Model Sex * } \\
\quad \text { Model Lea }\end{array}$ & $-4.18 \pm 1.86$ & -2.24 & 5.53 & 0.02 \\
\hline Model Sex & $1.51 \pm 1.41$ & 1.07 & 0.82 & 0.36 \\
\hline Model Leaf & $3.54 \pm 1.44$ & 2.46 & 2.40 & 0.12 \\
\hline \multicolumn{5}{|c|}{$\begin{array}{l}\text { Random effects: } \sigma_{\text {Territory }}^{2}=0.53, \sigma_{\text {visit }}^{2}=1.13 \\
\text { e) Number of duets (negative binomial GLMM) }\end{array}$} \\
\hline \multicolumn{5}{|l|}{ Model Leaf } \\
\hline Model Leaf & - & - & 1.37 & 0.24 \\
\hline Model Sex & & - & 2.26 & 0.13 \\
\hline \multicolumn{5}{|c|}{ Random effects: $\sigma_{\text {Territory }}^{2}=1.66 \times 10^{-7}, \sigma_{\text {Visit }}^{2}=1.92 \times 10^{-7}$} \\
\hline
\end{tabular}

in 12 of the 45 trials (26.7\%). The leaf display was performed by only one individual in eight of those trials (by three males and five females) and by both pair members in four trials. The probability that at least one member of the pair would display a leaf was affected by the interaction of model sex and model leaf display (Table 1d, Fig. 1d). The model's leaf display increased the probability that the pair would emit a leaf display when the model was female (emm contrast: $\beta=1.77 \pm 0.86, P=0.04)$, but had no effect when the model was male (emm contrast: $\beta=-0.31 \pm 0.59, P=0.59$, Fig. $1 \mathrm{~d}$ ). The 16 individuals that displayed a leaf during the experiment approached the model more closely than the 74 that did not display a leaf $(8.38 \pm 1.94 \mathrm{~m}$ versus $12.09 \pm 0.96 \mathrm{~m}$, Wilcoxon rank sum test; $\mathrm{W}=783.5, \mathrm{P}=0.04)$.

Pairs produced an average of $57.56 \pm 7.25$ duets; the number of duets was not affected by model sex, model leaf display, or their interaction (Table 1e, Fig. 1e).

\section{Discussion}

Our results show that territory owners respond differently when simulated intruders display a leaf than when they do not, but interestingly, this response depends on the sex of the model displaying the leaf. A territorial pair was more likely to approach to within $10 \mathrm{~m}$ and approached to a closer distance when a male intruder was displaying a leaf than when he was not. When the model was female, however, territory holders were more likely to respond with a leaf display when she was displaying a leaf than when she was not. In addition, pairs responded longer when the model was male, regardless of whether he displayed a leaf. Together, these results suggest that the leaf display has a signaling role during territorial encounters during the post-breeding season, and that while both sexes participate in the defense of established territories, their roles may differ during territorial intrusion.

In addressing the question of whether the leaf display in the russetcrowned motmot has an agonistic signaling function, some aspects of our results are consistent with criteria proposed to indicate aggressive signals in the context of passerine song (Searcy and Beecher, 2009). Searcy and Beecher's (2009) "response criterion" proposes that territory holders should respond differently to the putative signal than to an appropriate control stimulus. In this study, consistent with this criterion, display of a leaf by a simulated territorial intruder led to differences in territory holder response in the form of closer approach (increased probability of approach within $10 \mathrm{~m}$ and closer distance of closest approach; Figs. $1 \mathrm{~b}$ and 1c, respectively) toward male models and increased probability of leaf display toward female models (Fig. 1d). It is important to note, however, that fulfilling this criterion alone demonstrates only that the display has some "salience" to the responder, not that it is necessarily aggressive or agonistic (Searcy and Beecher, 2009).

The fact that this experiment was carried out when the focal pairs were not actively breeding and there was thus little threat of the intruder immediately reproducing (either socially or extra-pair) with one of the territory holders makes it less likely that the leaf display is a purely sexual signal. However, the same display could be used for agonistic signaling as well as for mate selection during other seasons or in other contexts. Indeed, it has been suggested that sexual selection is a special case of social selection, and that the selective pressures of choice and/or competition from conspecifics that shape the characters involved in signaling may be similar in sexual and non-sexual contexts, leading to similar types of signals, or even signals which are used in both contexts (West-Eberhard, 1983; Lyon and Montgomerie, 2012).

Searcy and Beecher's "predictive criterion" proposes that if a display is a signal of aggressive intent, there should be a positive association between the individual performing the display and subsequently escalating the conflict (e.g. approaching, attacking; Searcy and Beecher, 2009). When considering the behavior of the territorial motmots, the 16 individuals that displayed a leaf during the experiment approached the model more closely than the $\mathbf{7 4}$ that did not display a leaf, suggesting an association between an individual displaying a leaf and participating more intensely in the conflict. However, because this does not take into account the order of events, it is unclear whether this is because individuals displayed a leaf to signal their escalation or because more aggressive individuals both approach more closely and are more likely to display a leaf.

In addition to evaluating the role of the leaf display as a putative agonistic signal, our results provide some insight into sex roles in territorial defense in this species. First, our results showed that both members of the social pair participate in defending their established territory. Previous observations of russet crowned motmots have suggested relatively equitable division of labor in nest tunnel construction and territorial defense (Charre et al., 2017), and in our trials, in the majority of cases both pair members approached to within $10 \mathrm{~m}$ of the model. Both sexes participate in territorial defense in $87 \%$ of resident tropical passerines, where low annual mortality and stable territorial boundaries lead to few territorial vacancies and therefore to males and females being similarly highly invested in maintaining the territory (reviewed in Stutchbury and Morton, 2001). The high site fidelity, yearround territoriality, and relatively long lifespan of russet-crowned motmots likely lead to similarly balanced interests between the sexes in territory defense.

At the same time, differences in responses depending on the sex of the model can provide some insight into each sex's role in establishing (usurping) territories. Pairs responded longer to male than female models, suggesting that seeing a male evoked more vigilance by 
a)

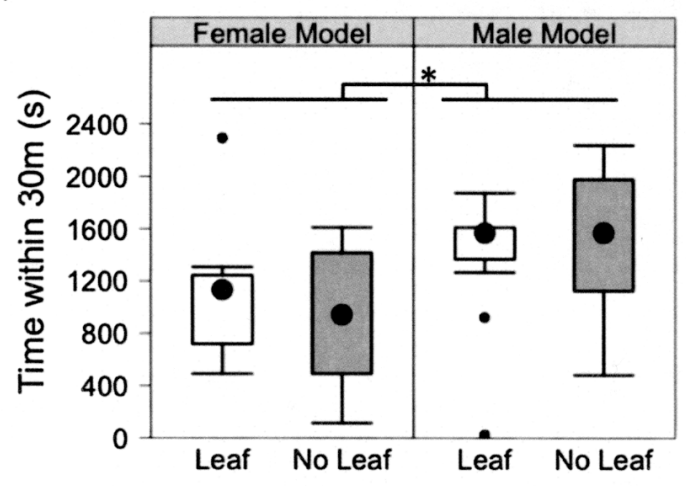

c)

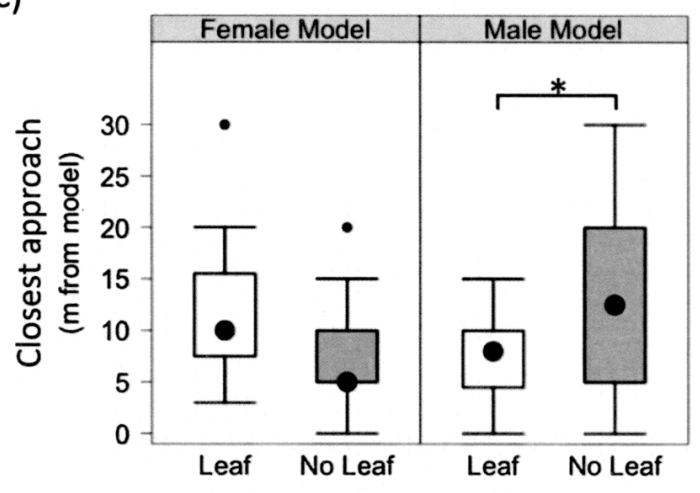

e)

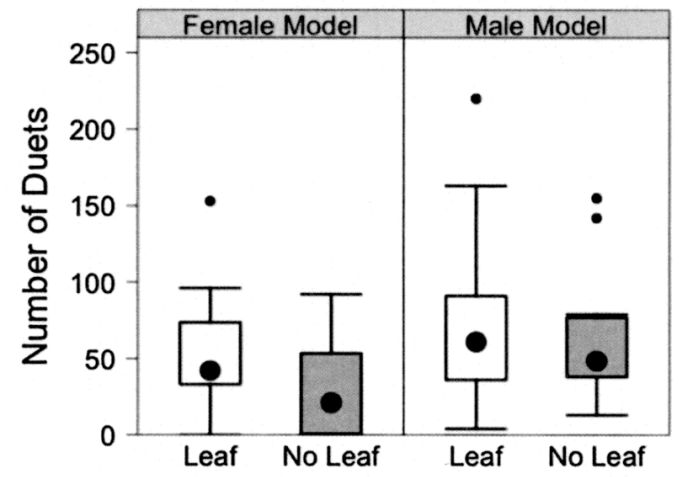

b)

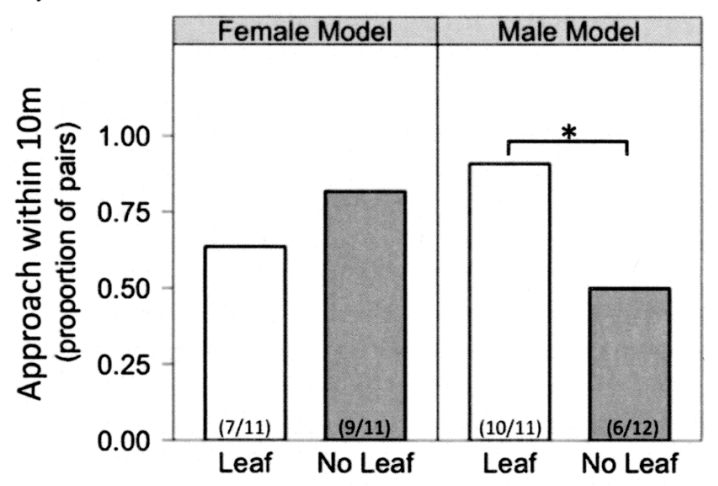

d)

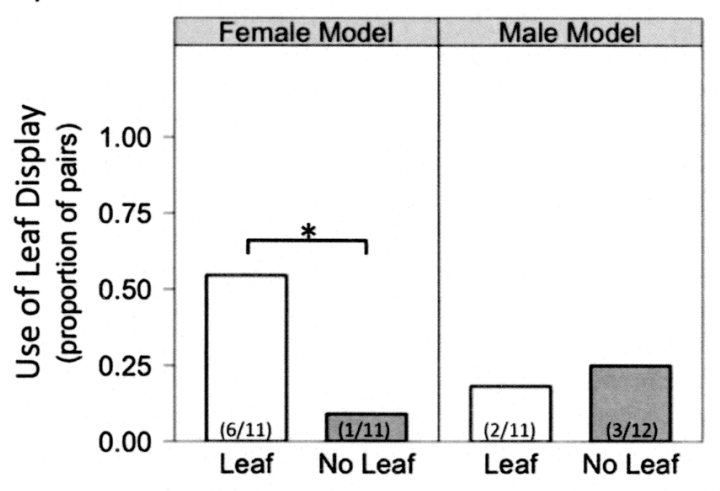

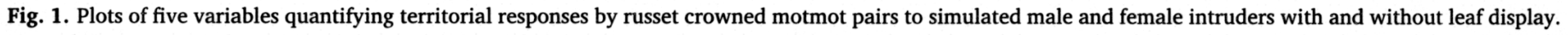

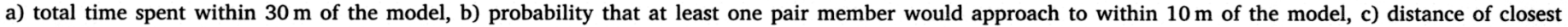

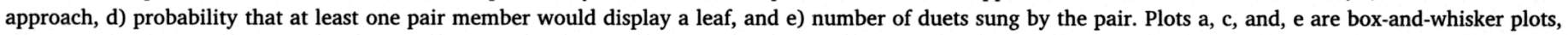

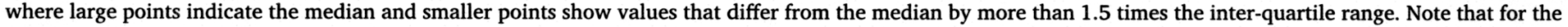

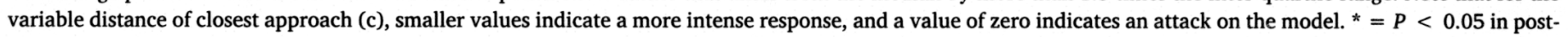
hoc comparisons; see results (Section 3.2) text and Table 1 for detailed results.

territorial pairs. Our finding that the leaf display by an intruder increased the probability of the owners approaching and the closeness of their approach when the intruder was male, but the probability of them reciprocating the display when the intruder was female (Fig. 1b, 1c) is consistent with game theory predictions if males are more threatening than females. Game theory models of territorial encounters suggest that the territory owner should attack immediately when confronted with a similarly able or motivated intruder, but pause or display before attacking when the intruder is less able or motivated than itself, allowing the intruder to retreat and avoiding a physical fight altogether (reviewed in Archer and Huntingford, 1994). Here, territory owners may have been more likely to display the leaf before approaching when the model intruder was female because females are less motivated or able to usurp the territory and thus more likely deterred by the leaf display alone. However, with a male model they may have skipped the leaf display and escalated directly to approach because males may be 
more motivated or able to usurp the territory.

Another possibility is that because we used recordings of duets, upon seeing a female model the territory owners may have assumed that the intruder's mate was nearby but not visible. Thus, the territory owners' leaf displays may have been directed toward the (hidden) male of the intruding pair, signaling their willingness to defend the territory and remaining available to approach the male intruder once he became visible. More detailed observations that explicitly consider the order of events during simulated territorial intrusions with and without the leaf display are needed to establish if this is the case. In either case, our data suggest that while males and females both contribute to nest building and territory defense once a territory is established (Charre et al., 2017), their roles in initial territory acquisition or usurping previously claimed territories differ. It may be informative to carry out a similar experiment using single-sex vocalizations as the playback stimulus to test territory holders' reactions to single (perhaps unpaired) intruders with and without a leaf.

While our experimental approach does provide new insights, much remains to be explored to understand the function and dynamics of the leaf display in russet-crowned motmots and how the leaf display interacts with other aspects of territorial signaling such as vocalizations. Observations of territorial behavior in this species are scarce, and many basic questions are still unanswered, including how often territorial owners are ousted by intruders, whether intruders are always paired birds or may be individual "floaters", whether a potential usurper acts alone or with its social mate, and whether pairing occurs before or after territory acquisition. Further observation of both pairs and floater males and females before nest building is needed to clarify whether one sex is more involved in finding and staking claim to territories, and temporary experimental removal of one or both territory holders to induce territory turnover would be highly informative. In addition, nothing is known about the importance of the size, shape, and color of the leaf used in the display. Given that this is one of only a handful of species to incorporate props into an agonistic display, further descriptive and experimental work could shed light on the role of this interesting signaling modality.

\section{Acknowledgements}

We thank Vanya Rohwer for preparation of taxidermic models and for help in the field. Funds for this work were provided by PRODEP UAEMOR CA54, and by the National Science Foundation International Research Fellowship Program and Americas Program (0700953) to TGM. LMK was funded by a PRODEP (Programa para el Desarrollo Profesional Docente) postdoctoral fellowship from the Mexican government.

\section{References}

Anderson, R.C., DuBois, A.L., Piech, D.K., Searcy, W.A., Nowicki, S., 2013. Male response to an aggressive visual signal, the wing wave display, in swamp sparrows. Behav. Ecol. Sociobiol. (Print) 67 (4), 593-600. https://doi.org/10.1007/s00265-013-
1478-9.

Animal Behaviour Society, 2012. Guidelines for the treatment of animals in behavioural research and teaching. Anim. Behav. 83 (1), 301-309. https://doi.org/10.1016/j. anbehav.2011.10.031.

Archer, J., Huntingford, F., 1994. Game theory models and escalation of animal fights. In Potegal, M., Knutson, J.F. (Eds.), The Dynamics of Aggression: Biological and Social Processes in Dyads and Groups. Lawrence Erlbaum Associates, Hillsdale, NJ, pp. 3-31.

Bradbury, J.W., Vehrencamp, S.L., 1999. Territorial signaling games. Principles of Animal Communication, 1st ed. Sinauer Associates, Sunderland, pp. 711-742.

Brooks, M.E., Kristensen, K., van Benthem, K.J., Magnusson, A., Berg, C.W., Nielsen, A. Skaug, H.J., Maechler, M., Bolker, B.M., 2017. glmmTMB balances speed and flexibility among packages for zero-inflated generalized linear mixed modeling. R J. 9 (2), 378-400.

Chaine, A.S., Roth, A.M., Shizuka, D., Lyon, B.E., 2013. Experimental confirmation that avian plumage traits function as multiple status signals in winter contests. Anim Behav. 86 (2), 409-415. https://doi.org/10.1016/j.anbehav.2013.05.034.

Charre, G.M., Paniagia, O., Osorio-Beristain, M., 2017. Limitation in reproductive success of a burrow nesting bird (Momotus mexicanus) during a humid season. West. N. Am. Nat. 77, 230-236. https://doi.org/10.3398/064.077.0211.

Crawley, M.J., 2007. The R Book. John Wiley \& Sons, Ltd., Sussex, England.

García-Navas, V., Valera, F., Griggio, M., 2015. Nest decorations: an "extended" female badge of status? Anim. Behav. 99, 95-107. https://doi.org/10.1016/j.anbehav.2014 10.024 .

Gaviño de la Torre, G., 2015. Aves De Morelos: Estudio General, Guía De Campo Y Recopilación Biológica. UAEM-CONABIO., Mexico City.

Hartig, F., 2019. DHARMa: Residual Diagnostics for Hierarchical (Multi-Level / Mixed) Regression Models. R Package.

Howell, S.N.G., Webb, S., 1995. A Guide to the Birds of Mexico and Northern Central America. Oxford University Press, Oxford.

Laidre, M.E., Vehrencamp, S.L., 2008. Is bird song a reliable signal of aggressive intent? Behav. Ecol. Sociobiol. (Print) 62 (7), 1213-1216. https://doi.org/10.1007/s00265 008-0569-5.

Lenth, R., 2018. emmeans: Estimated Marginal Means, Aka Least-squares Means. R Package Version 1.2.3. https://CRAN.R-project.org/package $=$ emmeans.

Lyon, B.E., Montgomerie, R., 2012. Sexual selection is a form of social selection. Philos Trans. R. Soc. Lond. B Biol. Sci. 367, 2266-2273 https://doi.org/doi: 10.1098/ rstb.2012.0012.

McGregor, P.K., 2000. Playback experiments: design and analysis. Acta Ethol. 3, 3-8. https://doi.org/10.1007/s102110000023.

Montgomerie, R., 2006. Cosmetic and adventitious colors. Bird Coloration Volume 1: Mechanisms and Measurements. pp. 399-430.

Murphy, T.G., 2008. Display of an inedible prop as a signal of aggression? Adaptive significance of leaf-display by the turquoise-browed motmot, Eumomota superciliosa. Ethology 114 (1), 16-21. https://doi.org/10.1111/j.1439-0310.2007.01421.x.

Murphy, T.G., Rohwer, V.G., Scholes, E., 2010. Breeding biology and longevity of Russetcrowned Motmots in central Mexico. J. Field Ornithol. 81 (1), 13-16. https://doi. org/10.1111/j.1557-9263.2009.00255.x.

Murphy, T.G., Rosenthal, M.F., Montgomerie, R., Tarvin, K.A., 2009. Female American goldfinches use carotenoid-based bill coloration to signal status. Behav. Ecol. 20 (6), 1348-1355. https://doi.org/10.1093/beheco/arp140.

Penteriani, V., del Mar Delgado, M., 2008. Owls may use faeces and prey feathers to signal current reproduction. PLoS One 3 (8), e3014. https://doi.org/10.1371/ journal.pone.0003014.

Reyes, D., Alcala, R.E., Arias, D., Osorio-Beristain, M., 2009. Genetic structuring At a fine scale in the russet-crowned motmot (Momotus mexicanus) in a tropical dry forest in Central Mexico. West. N. Am. Nat. 69 (2), 171-174. https://doi.org/10.3398/064. 069.0204 .

Searcy, W.A., Beecher, M.D., 2009. Song as an aggressive signal in songbirds. Anim. Behav. 78 (6), 1281-1292. https://doi.org/10.1016/j. anbehav.2009.08.011.

Sergio, F., Blas, J., Blanco, G., Tanferna, A., Lopez, L., Lemus, J.A., Hiraldo, F., 2011. Raptor nest decorations are a reliable threat against conspecifics. Science 331 (6015), 327-330. https://doi.org/10.1126/science.1199422.

Stutchbury, B.J., Morton, E.S., 2001. Behavioral Ecology of Tropical Birds. Academic Press, San Diego,

West-Eberhard, M.J., 1983. Sexual selection, social competition, and speciation. Q. Rev Biol. 58, 155-183. 